\title{
MICROBACIAS II: ERROS E ACERTOS DA GESTÃO PÚBLICA E PRIVADA - ESTUDO DE CASO FAOP
}

\author{
Alessandra, Alexandre Godinho
}

Universidade do Oeste Paulista - UNOESTE, Presidente Prudente, SP. E-mail: bertoncello@unoeste.br

\begin{abstract}
RESUMO
São realizados seletivos projetos com recursos públicos que visam o desenvolvimento econômico e social voltados para a agricultura rural. Entre as atividades agrícolas na região, a fruticultura vem obtendo destaque na produtividade agrícola do Oeste Paulista. Microbacias II é um instrumento moderno de política pública e a FACIC Jr aprovou um plano de negócio para a construção dos Centros de acolhimento e despolpadeira na região de Presidente Prudente. Este artigo vem demonstrar os ganhos, os problemas e as consequências econômicas dos desdobramentos da execução deste plano de negócio, bem como à importância do planejamento e do profissionalismo para o alcance de resultados eficientes. O principal objetivo foi monitorar a proposta da FAOP junto ao Microbacias II. Os resultados mostraram que os problemas são oriundos da dificuldade de gestão, da falta de informação e principalmente da burocratização. Os resultados confirmaram as teses de notáveis autores no assunto, que afirmam que não basta obter recursos públicos, as políticas devem ter aderência e a gestão interna eficaz para melhorar a eficiência da região. A metodologia foi pautada na abordagem qualitativa, pesquisa bibliográfica e sites públicos e jurídicos.
\end{abstract}

Palavras-chave: Microbacias II. Gestão. Sistema de Informação. Economia. Associação.

\section{MICRO-BASINS II: ERRORS AND HITS IN THE PUBLIC AND PRIVATE MANAGEMENT - THE FAOP CASE STUDY}

\begin{abstract}
Selective projects are carried out with public resources that aim the economic and social development focused on rural agriculture. Among the agricultural activities in the area, fruitgrowing has been highlighting in agricultural productivity of Oeste Paulista. Micro-basins II is a modern instrument of public policy and the FACIC Jr has approved a business plan for the construction of reception Centers and a depulper in the area of Presidente Prudente. This article demonstrates the gains, the problems and the economic consequences of unfolding the implementation of this business plan, as well as the importance of planning and professionalism for achieving efficient results. The main objective was to monitor the proposal of FAOP by the Micro-basins II. The results showed that the problems came from the difficulty of management, lack of information and mainly from bureaucratization. The results confirmed the thesis of remarkable authors on the subject, who claim that it is not enough to obtain public resources, policies should have adherence and effective internal management to improve efficiency in the area. The methodology was based on a qualitative approach, bibliographic research and public and juridical sites.
\end{abstract}

Keywords: Micro-basins II. Management. Information System. Economy. Association. 


\section{INTRODUÇÃO}

A região do Oeste Paulista emana produtores rurais. Estes por sua vez, buscam em meio as turbulências do ambiente externo, se manterem firme no mercado em que atuam. Os produtores rurais almejam caminhos para o desenvolvimento, visando o crescimento econômico.

Por meio do Microbacias II Acesso ao Mercado, os produtores rurais podem ampliar as oportunidades de renda, fortalecer a cadeia produtiva e aumentar a capacidade de negociação com o mercado, aumentando assim a competitividade da agricultura familiar.

Este programa tem se destacado como uma das ferramentas mais utilizadas pelo governo do Estado de São Paulo para beneficiar associações e cooperativas rurais, teve início em 2000 com o nome de Microbacias Hidrográficas. $\mathrm{Na}$ época, o objetivo foi incentivar práticas que proporcionasse condições do pequeno produtor combater a erosão do solo e a recuperação da mata ciliar.

A primeira fase foi concluída em 2008 e durante esses 9 anos, beneficiou mais de 400 associações segundo a Coordenadoria de Assistência Técnica Integral (CATI), esse resultado proporcionou a regulamentação de inúmeras pequenas propriedades rurais que estavam fora de conformidade ambiental segundo a lei vigente.

O início da segunda fase do projeto, batizada de Microbacias II, tem um foco diferente, pretende melhorar o acesso ao mercado para o pequeno produtor rural, assim o Decreto no 56.449 de 2010 prevê um orçamento de USD\$ 130 milhões, sendo 78 milhões de dólares provenientes do Banco Mundial e 52 milhões do Governo do Estado de São Paulo, contempla projetos que busquem agregar valor aos produtos rurais $\mathrm{e}$ facilitem a comunicação com o mercado (SÃO PAULO, 2010a).

O Microbacias II tem um formato menos rígido que o primeiro programa, com uma visão sistêmica, contempla não apenas o investimento nas cooperativas e associações, mas também o monitoramento e a extensão rural por parte da CATI, da mesma forma que coopera com os municípios envolvidos na melhoria da infraestrutura dos municípios (SÃO PAULO, 2010a).

Apesar de ser um instrumento mais refinado de política pública as últimas informações disponíveis no site da CATI $^{1}$ demonstram uma diminuição no número de associações e cooperativas beneficiadas, as cinco chamadas públicas atraíram 458 cartas de intenções 358 propostas entregues a até o

\footnotetext{
${ }^{1}$ http://www.cati.sp.gov.br/microbacias2/resultados-iniciativas$\underline{\text { negocio }}$
} 
momento 165 projetos aprovados, ou seja, contemplou até agora aproximadamente
$58 \%$ menos associações/cooperativas que o Microbacias Hidrográficas (2000/2008).

Quadro 1. Resultados parciais do Microbacias II

\begin{tabular}{|l|l|l|l|l|l|}
\hline Chamadas & Interesses & Entregues & Aprovados & Habilitados & Valores \\
\hline 1 & 135 & 92 & 38 & 36 & $\mathrm{R} \$ 14.79$ milhões \\
\hline 2 & 103 & 98 & 40 & 40 & $\mathrm{R} \$ 16,90$ milhões \\
\hline 3 & 65 & 38 & 35 & 35 & $\mathrm{R} \$ 14.31$ milhões \\
\hline 4 & 65 & 60 & 52 & - & $\mathrm{R} \$ 21.90$ milhões \\
\hline 5 & 90 & 70 & - & - & - \\
\hline
\end{tabular}

Fonte: Dados do site http://www.cati.sp.gov.br/microbacias2/resultados-iniciativas-negocio acessado 14 agosto de 2015, elaborado pelos autores.

Neves Neto (2013) aponta como possível entrave do processo, o limite de recursos por proposta que é de $\mathrm{R} \$ 800 \mathrm{mil}$ reais, e o teto mínimo de $70 \%$ dos agricultores envolvidos obrigatoriamente devem ser agricultores familiares, adequada essas premissas, a associação ou cooperativa tem direito a um subsídio de $70 \%$ dos investimentos contemplados no plano de negócios colocado na proposta.

No entanto para a execução do plano de negócio é preciso um bom planejamento de gestão para que o projeto possa ser realizado conforme prescrito. A Associação dos Fruticultores Associados do Oeste Paulista - FAOP - foi contemplada na terceira chamada do programa, porém no caso da FAOP, o tempo tem sido uma das dificuldades encontradas, para a execução do projeto. Em presença deste aspecto a questão central deste trabalho é identificar e analisar quais são os problemas da FAOP no
Microbacias II. Dentro deste enfoque é considerado nesta pesquisa aprofundar os métodos de gestão, o planejamento e as consequências econômicas dos desdobramentos da execução do plano de negócio.

\section{METODOLOGIA}

O caminho a ser percorrido é de extrema importância, já que orienta os meios, para se atingir os resultados esperados.

O ajustamento do método é assaz para o bom andamento da pesquisa, já que estará moldada para percorrer caminhos preestabelecidos e acentuados. (OLIVEIRA, 1999). Confere que a metodologia é composta por vários métodos que combinados formam um processo, que visa guiar para a discussão das premissas básicas do estudo, baseados em regras e procedimentos científicos. 
Portanto, em consideração aos objetivos da pesquisa, esta, foi pautada na abordagem qualitativa, constou de pesquisa bibliográfica, pois almejou compreender alguns termos, políticas públicas para 0 desenvolvimento rural com foco na agricultura familiar, a importância do planejamento, profissionalismos dos envolvidos, e os impactos econômicos.

\section{RESULTADOS}

As evidências disponíveis demonstram que o programa Microbacias II, traz um viés moderno do ponto de vista do desenvolvimento regional rural e que em conjunto com outros programas governamentais tais como PPA, PNAE, PPAIS podem cooperar para o desenvolvimento sustentável da agricultura familiar. Porém fica evidente pelos números atuais que as metas ainda não foram alcançadas por nenhuma das partes e assim não atingem o grau civilizatória almejado por Sachs (2015).

Entre os municípios do estado de São Paulo apenas $47 \%$ deles realizaram a implementação das compras locais de agricultura familiar conforme a Lei $11.947 / 2009$ em todas as suas etapas segundo Villar et al. (2013). Ao mesmo tempo o programa Microbacias II contemplou uma quantidade menor de associações e/ou cooperativas na sua primeira fase. Concomitantemente observamos a FAOP e o município de Narandiba ambos na mesma situação, todos os dois contemplados com o programa, mas ainda não usufruíram dos benefícios para fomentar a associação e o município.

As propostas aprovadas proporcionam ao município onde estão as associações a possibilidade de melhorias da infraestrutura municipal nas estradas, com as seguintes premissas; até $6,25 \mathrm{~km}$ de estradas rurais com trechos críticos podem ser reformadas com um custo total por quilometro de $\mathrm{R} \$ 49.571,00$ e um apoio do programa de $80 \%$ dos custos, contempla também, um total máximo de $30 \mathrm{~km}$ de manutenção de estradas rurais podendo ter um custo por quilometro de $\mathrm{R} \$ \mathbf{4} .256,00$ e o subsidio de $80 \%$ (SÃO PAULO, 2010 b).

A FAOP conta com a parceria da FACIC $J R^{2}$ desde a elaboração do Plano de negócio do Microbacias II. Essa parceria é fundamental, pois a FACIC JR oferece, a um custo bem menor que o do mercado, assessoria, consultoria e treinamento. Além disso, a FACIC JR vem elaborando diversos projetos do programa Microbacias II, e isso vem aumentando a sua credibilidade junto a esse programa.

O Projeto Centros de Acolhimento e Despolpadoras de Frutas do Oeste Paulista além de uma nova estrutura no

\footnotetext{
${ }^{2}$ Empresa Junior, dos cursos de Administração, Ciências Contábeis, Tecnologia em Gestão Comercial, Recursos Humanos e Tecnologia em Agronegócios. Onde os alunos colocam em prática o aprendizado em sala de aula.
} 
armazenamento e transporte das frutas, contempla dois barracões com tratamento do uso da água por decantação e uma camioneta de até 750 quilos, duas câmaras frias de resfriamento (uma de dimensões medias e outra grande), da mesma forma duas câmaras frias de congelamento (uma de dimensões pequenas e média), uma despolpadora de 3 tanques de lavagem de fruta, embaladora, mesa e equipamentos para manufaturar frutas, além de desenvolvimento e registro da futura marca das polpas e site para a divulgação.

Os atrasos estão presentes em algumas propostas do programa Microbacias II, mas este trabalho não teve como objetivo observar e monitorar todos os projetos, e sim a proposta da FAOP, onde foi constatado um atraso estrutural de um ano, de quando a proposta foi em abril de 2014 demoramos 8 meses para habilitar a proposta, por questões burocráticas e após a habilitação o cronograma foi refeito e mesmo assim, a FAOP já tem dificuldades em cumpri-lo, pois teve início em abril de 2015 e já está com atraso de 3 meses.

Esses atrasos causaram vários problemas, o mais evidente é a alteração média de preços no período, a inflação acumulada de fevereiro 2014 até agosto de 2015 supera 15\%, essa variação seguramente causará prejuízos para a Associação na compra dos produtos propostos. Porém o atraso tem maior impacto no faturamento previsto, dentro do cronograma após a implantação do "centro de acolhimento e despolpadores de frutas do Oeste" aumentaria o lucro líquido total a ser dividido entre os associados em $\mathrm{R} \$ 286.941,94$, sem a funcionamento dos centros o faturamento extra não acontecerá.

E por fim levando em consideração o momento grave que vive as contas públicas, o valor já alocado para o investimento também está sofrendo desvalorização por conta da inflação e não pode ser utilizado para outro fim, desta forma é também correto afirmar que apesar da viabilidade econômica do projeto que apresentou um Payback descontado inferior a 3 anos, o valor de $\mathrm{R} \$ 351.095,00$ do projeto, sendo $\mathrm{R} \$$ 245.766,50 a fundo perdido está sendo subutilizado e não cumpre seu papel de cooperar com o desenvolvimento rural e regional.

Da mesma forma que os recursos para melhorar as estradas rural também ainda não foram utilizados, lembrando que caso seja pedido o valor máximo em quilômetros contemplado teríamos um investimento público total de $\mathrm{R} \$ \mathbf{4 3 7 . 4 9 8 , 7 5}$ que não foram investidos na região.

\section{DISCUSSÃO}

As políticas públicas que visam o desenvolvimento, podem ter várias faces, 
entre as mais utilizadas, observa-se modelos endógenos que visam o desenvolvimento de dentro para fora, baseado no conhecimento local e no uso dos recursos disponíveis sejam ele de capital, humano, natural e financeiro. Grande parte do desenvolvimento rural europeu aconteceu desta forma segundo High e Nemes (2006).

O outro modelo é o exógeno que foi utilizado fortemente no século $X X$ e responsável pelo desenvolvimento rápido do extremo leste asiático segundo Lee, Tee e Kim (2009), a carência de tecnologia para dominar recursos naturais ou a escassez de recursos financeiros podem ser sanadas com uma intervenção externa e acelerar o desenvolvimento local.

Contemporaneamente nasceu uma visão mista de desenvolvimento que contempla outros fatores e não apenas identificar qual é a mola propulsora do desenvolvimento. Sachs (2015) considera o desenvolvimento apenas quando contemplamos cinco pilares: social, ambiental, territorial, econômico e político. Esta pesquisa busca este tipo de análise, das políticas públicas, analisando não apenas os números quantitativos demonstrados pelo governo, mas também compreender os impactos em todos os stakeholders.

O entendimento se Sachs nos parece mais contemporâneo e principalmente é o que mais se aproxima das nossas leis que regem e direcionam os atores rurais $\mathrm{e}$ as políticas públicas do estado de São Paulo.

Outro fator importante a ser analisado são os atores envolvidos no processo, a proposta aprovada da FAOP foi desenvolvida por uma parceria entre a associação, a FACIC Junior UNOESTE e a CATI, compreender a importância da junção da sociedade civil, acadêmica e dos órgãos públicos, é de fundamental importância para a aplicabilidade dos conceitos de desenvolvimento territorial.

Esse movimento abre possibilidades sociais e desdobramentos sócio econômico de competitividade regional ainda pouco explorados no Brasil e quase inexistentes do Oeste Paulista. Acreditamos que a afirmação de que quanto mais interligadas e longas são as cadeias produtivas rurais maiores são os reflexos positivos para os envolvidos (BERTONCELLO, 2014), seja verdadeira também no Oeste Paulista.

Por fim durante a execução do projeto foi constatado a dificuldade de cumprir os prazos e do dialogo claro entre a FAOP e o governo, esse fato vem provocando atraso na execução do projeto causando apreensão para todos os envolvidos, por isso através de análise documental foi apontado ruídos de comunicação que podem ser melhorados e foi também analisado percas econômicas pelo atraso das obras através da 
análise documental e do valor monetário no passar do tempo.

Valiosa é a comunicação para o ser humano e para a sociedade, uma vez que sem ela as coisas não acontecem com eficiência. A comunicação leva a informação, e com tantas tecnologias condizentes, é mister excogitar os melhores meios para que esta flua eficazmente.

As empresas estão sempre
tentando melhorar a
eficiência em suas operações
a fim de conseguir maior
lucratividade.
ferramentas que os
administradores dispõem, as
tecnologias e o sistema de
informação estão entre as
mais importantes para atingir
os níveis de eficiência e
produtividade nas operações,
especialmente quando
combinados com mudanças
no comportamento da
organização e das práticas do
negócio. (LAUDON; LAUDON,
2007, p. 6)

Ao analisar a colocação dos autores, é possível admitir que o uso de tecnologias e dos sistemas de Informação contribuem para as operações das empresas, pois gera eficiência e agilidade em seus processos. Ainda mais atrelados a nossa atualidade, que está transformando o uso de papéis por computadores, como será apresentado neste artigo.

Comenta-se com frequência, a respeito da eficiência nas organizações, porém é precípuo conhecer sua importância, para isso o autor Moraes (2010, p. 73) explica:

$$
\begin{aligned}
& \text { A eficiência refere-se à } \\
& \text { relação entre os resultados } \\
& \text { obtidos e os recursos } \\
& \text { empregados. Existem diversos } \\
& \text { tipos de eficiência, que se } \\
& \text { aplicam a áreas diferentes do } \\
& \text { conhecimento. A eficiência } \\
& \text { representa uma medida } \\
& \text { segundo o qual os recursos } \\
& \text { são convertidos em } \\
& \text { resultados de forma mais } \\
& \text { econômica. }
\end{aligned}
$$

Dado o exposto, nota-se que ao empregar os recursos disponíveis da melhor maneira, alcançamos resultados satisfatórios levando a eficiência nas operações. É precípuo o gerenciamento das informações na tomada de decisão em uma organização.

Ainda Oliveira, (2003, p. 225) afirma que "Empresas, indivíduos e governos deverão incorporar os avanços tecnológicos a suas respectivas realidades se ainda não o fizeram. A eficiência máxima depende da capacidade de interconexão".

Sendo assim todos devem ter acesso às informações, e para isso a adoção da tecnologia é fundamental nesse processo. Estar constantemente informado atualmente leva a agilidade e bons resultados.

O valor da informação está associado ao seu uso final, ou seja, sua utilidade efetiva, onde dentro de um contexto possa ser relacionada e interpretada para transmitir conhecimento e permitir que a tomada de decisão seja otimizada [...]. Deve ter a capacidade de reduzir incertezas no momento da 
efetiva decisão, nem antes, nem depois. (NOGAS, LUZ E NAVARRO, apud LUZ, 2011, p. 35)

Assim, é preciso ter a informação de maneira otimizada, no momento certo, de maneira correta e com qualidade para a tomada de decisão. Para isso, existe o SIG (Sistema de Informações Gerenciais) onde podemos conhecer esta ferramenta como:

“[...] o processo de transformação de dados em informações, que são utilizadas na estrutura decisória da empresa como ferramenta que possibilita a sustentação administrativa para otimizar os resultados esperados," (OLIVEIRA, 2002, p. 65).

Isso quer dizer que as informações são tangenciadas e facilitadas para a tomada de decisão, seu uso leva a eficiência nos resultados. Para alimentar este sistema utiliza-se a digitalização de documentos e Avedon (1999, p. 184) traz seu conceito sendo o "uso de um escâner para converter documentos (em papel ou microfilmes) em imagens eletrônicas codificadas digitalmente e que são apropriadas para armazenamento magnético ou óptico."

Sendo assim, a digitalização é a transformação de documentos físicos em documentos virtuais, armazenados digitalmente, podendo ser encontrados com facilidade.

Vários fatores influenciaram os resultados que até o momento estão abaixo do esperado as dificuldades que os produtores encontram nesse caminho por serem pequenos produtores, no entanto como associação, podem melhorar as possibilidades de rentabilidade a longo prazo. O artigo 45, da Lei Do Associativismo e do Cooperativismo, Capítulo XI, abaixo transcrito, (BRASIL, Presidência da República, 1991) traz:

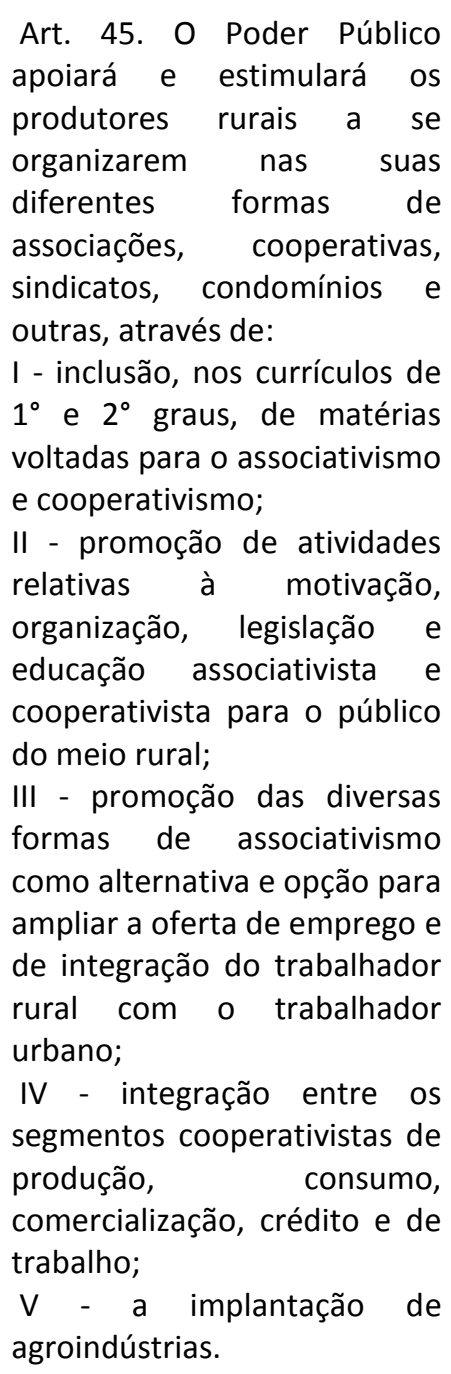

Diante disso observa-se que uma associação possui o apoio do poder Público, que facilita sua atuação, podendo este se beneficiar com isso. 
Além disso no artigo 16 e 17 da Lei Da

Assistência Técnica e Extensão Rural, Capítulo

V, (BRASIL, Presidência da República, 1991) traz outras colocações:

Art. 16. A assistência técnica e extensão rural buscarão rural, proprietário ou não, suas famílias e organizações, soluções adequadas a seus problemas de produção, gerência, beneficiamento, armazenamento,

comercialização,

industrialização, eletrificação, consumo, bem-estar e preservação do meio ambiente.

Art. 17. O Poder Público manterá serviço oficial de assistência técnica e extensão rural, sem paralelismo na área governamental ou privada, de caráter educativo, garantindo atendimento gratuito aos pequenos produtores e suas formas associativas, visando:

I - difundir tecnologias necessárias

ao aprimoramento da economia agrícola, à conservação dos recursos naturais e à melhoria das condições de vida do meio rural;

II - estimular e apoiar a participação e a organização da população rural, respeitando a organização da unidade familiar bem como as entidades de representação dos produtores rurais;

III - identificar tecnologias alternativas juntamente com instituições de pesquisa e produtores rurais;

IV - disseminar informações conjunturais nas áreas de produção agrícola, comercialização,

abastecimento agroindústria.

Art. 18. A ação de assistência técnica e extensão rural deverá estar integrada à pesquisa agrícola, aos produtores rurais e suas viabilizar, com o produtor

entidades representativas e às comunidades rurais.

Sendo assim uma Associação pode se desenvolver progressivamente, uma vez que o órgão Público fornece a assistência que os produtores rurais necessitam.

A Associação dos Fruticultores do Oeste Paulista (FAOP) do município de Narandiba e Presidente Prudente jazem em um ponto estratégico, com proximidade das propriedades. Com o apoio do governo Estadual visam a construção de Centros de Acolhimento e Despolpadoras de Frutas.

As mutações do ambiente em que estamos inseridos geram muitas incerteza e preocupações. Hodiernamente deve ter precauções ao traçar planos futuros, agir com prudência e prever os riscos do negócio. Importante salientar que a crise, a qual o País está passando, trouxeram muitas dificuldades para as empresas, associações e à sociedade em geral.

É importante saber trabalhar essa situação de forma a resolver e traçar caminhos, que levem ao alcance dos objetivos preestabelecidos. Segundo Chowdhury (2003, p.5):

Os Administradores devem
perceber a importância das
lições aprendidas. Os
fracassos ensinam como ter
sucesso no futuro. Quando
uma meta desejada não se
concretiza, muitos líderes
procuram uma fórmula
mágica em vez de 
Aceitar a realidade. Os líderes e gerentes do século XXI devem repensar os processos do século anterior.

Após essas ponderações, aprende-se que através de fatos ou acontecimentos passados ou até mesmo exemplos de outras pessoas podemos tirar grandes lições. Quando estas são aproveitadas de forma correta poderão trazer resultados para o futuro. Por isso há a necessidade de apreender constantemente, para que se use a estratégia correta para cada situação. Administrar não é uma tarefa fácil. É preciso pensar, raciocinar, analisar, avaliar e decidir. Conhecer o ambiente em que está inserido, a economia, os fatores externos e internos de uma organização são primordiais.

A FAOP (objeto de estudo deste artigo) apresenta diversas dificuldades. Dentre elas se destacam o ambiente externo, mais especificamente a economia. A inflação trouxe riscos inesperados aos Fruticultores. O plano de negócio elaborado a 1 ano atrás, hoje sofreu grandes alterações, principalmente nos preços. Para atingir o objetivo proposto em um plano de negócio, faz se fundamental uma Gestão eficiente. Para Padoveze e Taranto (2009, p. 4)

O processo de gestão consiste no ciclo sequencial das atividades administrativas de planejamento, execução e controle. E essa sequência, embora já consagrada, diferencia-se em sua aplicação nas empresas em função do modelo de gestão adotado. De fato, modelo de gestão é o conjunto de princípios que norteiam a gestão empresarial e decorrem da visão, missão, dos valores e da cultura da empresa.

Tal assertiva engloba o planejamento, a execução e o controle, que são fundamentais na alta administração. 0 modelo de gestão adotado pela associação é precípuo para o bom andamento do mesmo. Conforme o autor, estão interligados a gestão: a missão, visão, valores e a cultura da empresa. Tudo isso são os requisitos para uma boa Gestão, sem a qual não se consegue executar um bom plano de negócios.

É fundamental fazer uma análise econômica da situação atual, já que o momento difere do prescrito. $\mathrm{O}$ fato de os recursos naturais e econômicos serem escassos, faz se necessário melhorar a Gestão desses recursos. Uma boa gestão e gerenciamento trazem bons resultados.

Por outro lado, acreditamos que a burocracia vem atrapalhando o processo, futuras debates devem avaliar os entraves na compra dos programas governamentais, entre eles o problema mais evidente é o da licença de inspeção sanitária, a criação de consórcios municipais pode eliminar barreiras dos produtores rurais que têm apenas o SIM (Serviço de Inspeção Municipal) e fomentar o desenvolvimento rural. 
Ao mesmo tempo a exigência da criação de cooperativas e associações para que os agricultores familiares se beneficiem de programas como o Microbacias II, devem ser discutidas, como visto essas formas de organização proporcional ganhos aos agricultores que tem grande afinidade de pensamentos empreendedores, porém deixa a desejar quando entre os associados há pontos de vistas dicotômicos e pelo formato da Lei deixa o processo lento e por vezes paralisado, caso o programa contemplasse outras formas de cooperação comercial, como por exemplo o encadeamento produtivo poderíamos tem uma adesão maior ao projeto.

\section{CONCLUSÃO}

Fica claro a necessidade da continuidade e do aprimoramento das políticas públicas como os programas Microbacias II e PNAE, apesar da convergência entre elas e da clareza dos objetivos, em nenhum dos casos foi verificado o êxito total dos objetivos, de alguma sorte verificou-se vitorias parciais.

Os problemas não se limitam a esferas estaduais e federais como relatado a morosidade dos parceiros envolvidos fez com que os municípios deixassem de receber enormes aportes financeiros para a melhoria da infraestrutura rural, esses investimentos certamente colaborariam com o desenvolvimento do município e também o acesso ao mercado dos produtores rurais.

Por fim fica evidente que as lentidões não provêm apenas do setor público, a dificuldade de gestão interna e conhecimento das leis, faz da iniciativa privada envolvida. A FAOP deixou clara a fragilidade na sua gestão, evidenciando que são ótimos agricultores, mas que ainda comentem erros graves como empresários, desta forma também é evidente que a FACIC JR deveria estar mais presente no processo, facilitando a conversa entre os Stakeholders.

\section{REFERÊNCIAS}

AVEDON, D. M. GED de A a Z: tudo sobre Gerenciamento Eletrônico de Documentos. São Paulo: Cenadem, 1999.

BeRtOnCello, A. G. Poverty Reduction in rural areas of low-income countries in SubSaharan Africa. 106. ed. Saarbrücken: LAP LAMBERT Academic Publishing, 2014.

BRASIL. Congresso Nacional. Presidência da República Casa Civil. LEI № 8.171, DE 17 DE JANEIRO DE 1991. Dispõe sobre a política agrícola. Diário Oficial da União, Brasilia, DF, 17 Jan. 1991 Disponível em:< http://www.planalto.gov.br/ccivil_03/LEIS/L8 171.htm>. Acesso em: 06 ago. 2015.

\section{CHOWDHURY, S. Administração do Século}

XXI: o modo de gerenciar hoje e no futuro. Tradução Maria Lúcia G. L. Rosa. Revisão técnica Carlos A. Caldas Moraes. São Paulo: Person Education do Brasil, 2003.

HIGH C. e NEMES G., The Rural Citizen: Governance, Culture and Wellbeing in the 
$21^{\text {st }}$ Century, University of Plymouth Print, 2006 UK.

LAUDON, K. C.; LAUDON, J. P. Sistemas de Informação Gerencial. 7. ed. São Paulo:

Person Prentice Hall, 2007.

LUZ, E.E. Controladoria Corporativa. Curitiba: Ibpex, 2011.

LEE Y-S, TEE Y-C, KIM D-W. Endogenous versus exogenous development: a comparative study of biotechnology industry cluster policies in South Korea and Singapore. Environment and Planning C, Government and Policy, v. 27, p. 612-631, 2009. Doi 10.1068/c0881b.

MORAES, G. Elementos do Sistema de Gestão de Smsqrs: Teoria da Vulnerabilidade. 2. ed. Rio de Janeiro: GVC, 2010.

\section{NEVES NETO, C. C. Políticas Públicas \&}

Desenvolvimento Rural: O Programa de Microbacias I e II no Estado de São Paulo

Presidente Prudente: [s.n], 2013. .

OLIVEIRA, L. M.; PEREZ JR., J. H.; SILVA, C. A.

S. Controladoria Estratégica. São Paulo:

Atlas, 2002.

OLIVEIRA, J. F. T.I.C. Tecnologias da Informação e da Comunicação. São Paulo: Érica, 2003.

PADOVEZE, L. C.; TARANTO, F. C. Orçamento empresarial: novos conceitos e técnicas. São Paulo: Person Education do Brasil, 2009.

SACHS, J. D. The Age of Sustainable Development. Columbia University Press, 2015.

SÃO PAULO (Estado). Secretaria de Agricultura e Abastecimento e Secretaria do Meio Ambiente. Coordenadoria de Assistência Técnica Integral e Coordenadoria da Biodiversidade e Recursos Naturais. Projeto de Desenvolvimento Rural Sustentável. MICROBACIAS II - Acesso ao mercado. Anexo 1: Informações gerais da agropecuária do Estado de São Paulo, São Paulo, 2010 a.

SÃO PAULO (ESTADO), Secretaria de Agricultura e Abastecimento e Secretaria do Meio Ambiente, Coordenadoria de Assistência Técnica Integral e Coordenadoria da Biodiversidade e Recursos Naturais, Projeto de Desenvolvimento Rural Sustentável MICROBACIAS II (Acesso ao mercado). Anexo 12; Critérios de Atendimento de Municípios par Implantação de Gestão de Rede de Estradas Rurais e Obras e Serviços de Reabilitação de Segmentos Críticos e Manutenção, São Paulo 2010 b.

VILLAR, B. S. et al. Situação dos municípios do estado de São Paulo com relação à compra direta de produtos da agricultura familiar para o Programa Nacional de Alimentação Escolar (PNAE), Revista Bras Epidemiol., v. 16, n. 1, p. 223-6, 2013. http://dx.doi.org/10.1590/S1415-

790X2013000100021

Recebido para publicação em 19/08/2015

Revisado em 26/08/2015

Aceito em 10/09/2015 